\title{
Perspectivas relacionales frente al conflicto social: el compromiso del clínico relacional con la acción transformadora ${ }^{1}$
}

\author{
Alejandro Ávila Espada² \\ $I P R, I A R P P$
}

\begin{abstract}
Este trabajo introductorio muestra que nuestra responsabilidad como clínicos es comprometernos con la acción transformadora. Nuestra opción es tomar conciencia en la intersección entre la subjetividad y la compleja sociedad en la que vivimos. Nuestro silencio ya no es suficiente como clínicos, el "giro ético" nos espera como los relacionalistas que pretendemos ser. Memoria e historia son parte de nuestra esencia, y tenemos la posibilidad de integrarlo, tanto a lo largo de nuestro desarrollo personal, como profesionales llamados a actuar de una manera creativa y transformadora.
\end{abstract}

Palabras clave: Compromiso Social, Cambio Social, Psicoanálisis Relacional

This introductory paper shows that our responsibility as clinicians is to compromise ourselves with transformative action. Our choice is to gain awareness in the intersection of subjectivity and the complex society we live. Our silence is no longer enough as clinicians, the "ethical turn" wait us as the relationalists we intended to be. Memory and History are part of our essence, and we have the possibility to integer both along our personal development, but mainly as clinicians called to act in a creative and transformative way.

Key Words: Social Change, Social Compromise, Relational Psychoanalysis English Title: Relational Perspectives facing Social Conflict: The compromise of relational clinicians with transformative action.

\section{Cita bibliográfica / Reference citation:}

Ávila Espada, A. (2016). Perspectivas relacionales frente al conflicto social: el compromiso del clínico relacional con la acción transformadora. Clínica e Investigación Relacional, 10 (3): 723-727. [ISSN 19882939] [Recuperado de www.ceir.info ] DOI: 10.21110/19882939.2016.100307

\footnotetext{
${ }^{1}$ Traducción castellana del original inglés leído como discusión a la Sesión Plenaria: "Vitality in Contexts of Destruction", en la que el autor interviene como interlocutor y moderador (Plenary IV: IARPP Rome Conference, June 11, 2016: THE ARTS OF TIME. RELATIONAL PSYCHOANALYSIS AND FORMS OF VITALITY IN CLINICAL PROCESS).

${ }^{2}$ Catedrático de Personalidad, Evaluación y Tratamiento Psicológicos de la Universidad Complutense, Madrid, España. Presidente de Honor del Instituto de Psicoterapia Relacional, Madrid, España. Contacto: avilaespada@gmail.com
} 


\section{Una breve introducción a la discusión sobre Vitalidad en Contextos de Destrucción}

Un placer y un honor estar aquí participando como interlocutor de estos tres destacados contribuidores de nuestra comunidad relacional en IARPP, convocados para hablar de la vitalidad en contextos de destrucción. Las formas de las tendencias de destrucción dentro de nuestro mundo son diferentes a lo largo de las culturas y sociedades, pero muchos de los temas que comparten ellos hoy aquí son comunes a todos los presentes, sea cual sea su edad y procedencia cultural. En los textos que siguen a esta introducción se presentan y analizan tres contextos: las formas de cambiar en nuestra Europa, antigua y conservadora, mediante la creación y expresión de un arte políticamente comprometido, el "agit-prop", que Andrew Samuels nos presenta sin tapujos; las tensiones estructurales de supervivencia de una nación, Israel, donde su gente tiene que hacer frente al peso de los mitos marcados para cumplir con su destino y a la vez mantener espacios de realización personal y social, tal como nos muestra Chana Ullman; Las transformaciones complejas de una sociedad colonial (Sudáfrica) profundamente dividida en clases y razas hasta llegar a una "democracia real" que se esfuerza por alcanzar la madurez, tal como nos mostrará Sally Swartz.

Chana Ullman explora el significado de lo Heroico en contextos de destrucción a lo largo de dos ejes: una dialéctica intrapsíquica entre la vitalidad, la agencia e ideales persecutorios, y una construcción social de 'pasión y trauma'. Esta autora nos subraya cómo en el proceso psicoanalítico nos encontramos con una tensión entre el significado social de la autodestrucción personal o "sacrificio por los objetivos de la comunidad" y el "heroísmo ordinario" de reconocer nuestra vulnerabilidad y encontrarnos con el dolor del Otro. Para ayudar a la persona a hacer frente a esta lucha, nos enfrentamos tanto a las necesidades individuales como a las sociales, tal como se expresa en un notable trabajo cinematográfico (visto por muchos de nosotros durante la Conferencia de IARPP en Tel Aviv en 2009), Vals con Bashir ${ }^{1}$. Se necesita un viaje personal a través de las muchas facetas personales y sociales del trauma, para que cualquiera de nosotros devengamos sujetos de nuestro cambio en el eje de la conciencia social. Un viaje apenas emprendido en sociedades que no se han permitido revivir su memoria, tal es el caso de España, tras nuestra guerra civil de hace ya ocho décadas, con muchos relatos aún por hacer y descubrimientos por integrar. Pues sólo en las últimas décadas nos hemos empezado a enfrentar a nuestra "memoria histórica", tras más de tres cuartos de siglo, con muchos significados disociados y con la tarea de identificar una gran cantidad de enterramientos en lugares desconocidos, necesarios para ser integrados en nuestra comunidad como "Lugares de memoria"2 lugares reales pero no bien recuperados, en las que se produjeron los acontecimientos traumáticos de la historia, y generar una narrativa 
explícita y honesta que nos permita trascenderla. También con la retirada de símbolos de victoria o dimanación de unos sobre otros, en línea con lo que Swartz nos va a presentar.

Sally Swartz, en su contexto sudafricano, se pregunta si podría tal ruptura con el pasado haber ocurrido sin remover un símbolo, sin una representación colectiva de una caída, del derrumbe del símbolo de la dominación racial, en su propio centro universitario. Ella se pregunta que si no disponemos de una narrativa inclusiva, ¿cómo podremos construir un espacio tercero? El movimiento que hemos vivido en España el 15 de mayo (2011) ${ }^{3}$ comparte algunas facetas con lo que Sally nos narra, en el que la colectividad se despierta y tiene que hacer frente a una profunda transformación de la vieja política y sus agentes, los políticos, que en lugar de servir a la comunidad persiguen objetivos perversos, como se muestra en la corrupción generalizada entre algunos sectores de funcionarios y representantes sociales y políticos.

Andrew Samuels nos muestra que un profesional comprometido tiene muchas posibilidades de servir a la comunidad con una forma de vida políticamente comprometida, tanto como persona como en cuanto profesional. Principalmente, puede, como un "espectador activo" participar en los argumentos de la vida personal y social, sin identificarse con un héroe, sino como un agente. Es el uso de lo que denomina "agit-prop", arte o escenificación provocadora, que a través de un distanciamiento del drama humano personal -como en el teatro de Brecht-nos permite ver más en perspectiva lo que necesita ser cambiado en nuestra sociedad. Los psicoanalistas pueden ver - y mostrar- en perspectiva cómo las cosas pueden ser, no sólo como son, revelando las contradicciones de la conformidad social. Las potentes imágenes que Andrew nos mostrará, así como la escenificación de Pina Bausch4, me recuerda otra actuación evocadora que María Pagés ha presentado recientemente en todo el mundo, sobre las fuerzas transformadoras de la Mujer. A la voz femenina, María Pagés le pide y exige que tome la palabra para hablar de las mujeres, de lo que las mujeres sienten y viven. El Ser, entonces, es la aparición de la voz femenina, la voz de todas las mujeres, oculta por los mismos miembros de su género. Una voz y palabras que podemos oír y sentir ahora aquí brevemente ${ }^{5}$. Esa voz, testimonio de quien toma la palabra para conectar experiencia y sentido, es el reto al que estamos convocados.

\section{El compromiso del clínico relacional con la acción transformadora}

El cambio es una intersección de lo personal y lo colectivo. El cambio personal no es siempre posible o duradero sin el cambio social, y viceversa. Pero el cambio social 
necesita la presencia, la participación, con el ojo puesto en la transformación social que permite al individuo una experiencia de estar con otros en desarrollo. Una presencia, como dijo E. Levinas: "La presencia de personas en la fuerza de su identidad insustituible, en la fuerza de su inevitable responsabilidad"6. Esta presencia / participación supone el sacrificio de dejar el calor acogedor de nuestros mundos privados para vernos como parte de toda una sociedad. Pero no es un compromiso heroico, sino un compromiso de entrar en acción en cualquier momento, tenemos la oportunidad de estar presentes en lo colectivo.

Como Eyal Rozmarin han señalado recientemente7: "Nos sentimos vivos y con poder cuando sentimos que somos parte de algo, de que pertenecemos a colectivos con experiencias similares, identificaciones similares, fantasías similares. Tenemos que pertenecen para ser fuertes". Eso es la Vitalidad.

Nuestra opción es tomar conciencia en la intersección entre la subjetividad y la compleja sociedad en la que vivimos. Esa es nuestra historia como seres humanos, es inevitable que vivamos en contextos en los que las explicaciones y el significado sólo puede alcanzarse a través de un profundo conocimiento de nuestra posición en el contexto, donde cualquier acción u omisión es significativa. Eso es lo que Pichon Rivière llama "Sujeto situado" (Sujeto comprometido con el conocimiento de su agencia en el contexto). También tenemos que revisar nuestra posición como analistas-sujetos sociales que vivimos en una época, sociedad y contexto concreto.

Nuestro silencio ya no es suficiente como clínicos, el "giro ético" (Donna Orange, 2011, 2016) nos espera como los relacionalistas que pretendemos ser. Memoria e historia son parte de nuestra esencia, y tenemos la posibilidad de integrarlo, tanto a lo largo de nuestro desarrollo personal, como profesionales llamados a actuar de una manera creativa y transformadora. Como hemos expresado junto a Steven Knoblauch en el reciente colloquium ${ }^{8}$ de IARPP, continuamos con el espíritu de Stephen Mitchell para explorar y expandir las fronteras de temor y esperanza.

Gracias Chana, Sally y Andrew por pensar juntos sobre esta encrucijada, nuestro lugar como sujetos con agencia transformadora tanto en nuestro papel como personas y como profesionales.

\section{REFERENCIAS}

Orange, D.M. (2011). The Suffering Stranger: Hermeneutics for Everyday Clinical Practice. Nueva York: Routledge expresa. Este material es para uso científico y profesional exclusivamente y puede contener información clínica sensible. Los editores no se responsabilizan de los contenidos de los autores. Dirigir las consultas sobre derechos y autorizaciones a ceir@psicoterapiarelacional.es 
Orange, D.M. (2016). Nourishing the Inner Life of Clinicians and Humanitarians; The ethical turn in Psychoanalysis New York: Routledge.

Samuels, A. (1993). The Political Psyche. London and New York: Routledge

Samuels, A. (2001). Politics on the Couch: Citizenship and the Internal Life. London and New York: Karnac Books/Other Press.

Samuels, A. (2014). Persons, Passions, Psychotherapy, Politics London and New York: Routledge. Samuels, A. (2015). A New Therapy for Politics? London: Karnac.

Original recibido con fecha: 1-6-2016 Revisado: 30-8-2016 Aceptado: 31-10-2016

NOTAS:

\footnotetext{
${ }^{1}$ Realizada por Ari Folman (2008). See: $\mathrm{http} / / \mathrm{www}$.imdb.com/title/tt1185616/reviews?ref_=tt_ov_rt

${ }^{2}$ Véase: https://en.wikipedia.org/wiki/Historical Memory Law y también estos otros:

https://www.youtube.com/watch?v=F_TaL3Oh8IE/

http://www.genocidescholars.org/sites/default/files/document\%0g\%5Bcurrent-

page $\% 3$ A1\%5D/documents/IAGS\%202011\%20Daniel\%20Stofleth.pdf /

3 Véase: https://en.wikipedia.org/wiki/Anti-austerity_movement_in_Spain

${ }_{4}^{4}$ Café Muller (Pina Bausch, 1980). Véase en: https://vimeo.com/36445063

${ }^{5}$ Se incluye en este momento de la presentación en Roma un breve corte de vídeo de la actuación de María Pagés ("Yo, Carmen". 2015-17. Véase: http://www.mariapages.com/en yo-carmen.html)

${ }^{6}$ Emmanuel Levinas, Alterity and Transcendence, 1999.

7 En el coloquio celebrado en IARPP sobre su trabajo "I am Yourself" (Rozmarin, Eyal (2009). 'I Am Yourself: Subjectivity and the Collective', Psychoanalytic Dialogues, 19: 5, 604-616)

${ }^{8}$ Coloquio de IARPP celebrado en Mayo 2016: "Subjectivity and the Collective: Encountering the Political in Psychoanalysis" en el que se ha debatido a partir del mencionado trabajo de Eyal Rozmarin.
} 